\title{
Modelos compositivos en los primigenios refraneros castellanos
}

Alicia Esther Ramadori

UNS

\begin{abstract}
Resumen
Las primeras recopilaciones castellanas de refranes se producen en el siglo XV, mostrando ya diferentes modalidades de organizar las paremias: Seniloquium aúna el ordenamiento alfabético de los refranes en lengua romance con comentarios latinos; los Refranes que dizen las viejas tras el fuego son una compilación de refranes autónomos y yuxtapuestos en series también alfabéticas; los Refranes famosissimos y prouechosos glosados se integran y subordinan en un discurso de temática moral. El origen de estos modelos compositivos se produce en el ámbito escolar y se relaciona con la corriente letrada de la literatura de sentencias que se inicia en Castilla en el siglo XIII. Los tres paradigmas estructurales son determinantes en el desarrollo de los refraneros españoles.
\end{abstract}

\section{Palabras clave}

Paremiología - Marqués de Santillana - Refranes que dizen las viejas - Seniloquium - Refranes glosados

En España, la recopilación de refranes en colecciones autónomas es tardía pues recién sucede en el siglo XV, a diferencia de la práctica de inserción de proverbios en la literatura que se testimonia desde los primeros textos escritos en lengua romance o de la compilación de sentencias que se realiza en el siglo XIII. El primer refranero, el Seniloquium o Refranes de los viejos, se conserva en copia manuscrita de fines del siglo $\mathrm{XV}$, mientras que otras dos colecciones coinciden en ser impresas en los primeros ańos del siglo XVI: los Refranes que dizen las viejas tras el fuego ( $1^{\circ} \mathrm{ed}$. de 1508 por Jacobo Cromberger en Sevilla) y los Refranes famosissimos y prouechosos glosados $\left(1^{\circ}\right.$ ed. de 1509 en la imprenta burgalesa de Fadrique de Basilea). Estos tres refraneros muestran tres modelos compositivos diferentes. El primero corresponde al Seniloquium donde aparecen refranes castellanos ordenados alfabéticamente, sin embargo, resulta más relevante que estén acompanados con glosas explicativas en latín. En el segundo tipo de organización, los Refranes que dizen las viejas tras el fuego siguen también el orden por a.b.c., aunque en este caso se compilan como una serie de refranes yuxtapuestos e independientes entre sí. En el tercer modo de los Refranes glosados, se da la integración de los refranes configurando un discurso adoctrinador de carácter moral.

La existencia de diferentes paradigmas estructurales está asociada a la cuestión del origen del refranero medieval. Hugo O. Bizzarri (2004: 90-96) señala el carácter esporádico y aprogramático de estos primeros refraneros, contrariamente al surgimiento de las colecciones sapienciales en los siglos XIII y XIV, que nacieron como apoyo de la reforma legislativa impulsada por la corona española. En cambio, el entorno donde hay que buscar la procedencia 
de las compilaciones de refranes es el ámbito escolar, especialmente a partir de las circunstancias que produjo la reforma educativa del siglo XI, al propiciar el ejercicio de la escritura proverbial para la enseñanza gramatical y moral. Teniendo presente el amplio fenómeno románico en el que se inscriben las manifestaciones hispánicas, a continuación describiré los modelos compositivos que exponen estos tres refraneros españoles, tratando de recuperar las condiciones de producción y recepción a partir de los mismos textos y de los datos que aportan los estudios editoriales.

\section{Seniloquium}

Seniloquium, colección manuscrita de casi quinientos refranes castellanos, se particulariza por las glosas escritas en latín que los interpretan desde una doble perspectiva jurídica y ética cristiana, e incluso, en ocasiones les adjudican una explicación histórica o anecdótica. Se conserva en dos códices: uno, perteneció a la Biblioteca Provincial de Segovia y pasó a la Biblioteca Nacional de Madrid (Ms.19343) catalogado como anónimo y sin data. En él se transcriben 495 títulos de refranes, destacados con tinta roja, con sus respectivos comentarios latinos; está escrito en letra gótica cursiva del siglo XV. El otro manuscrito se encuentra en la Biblioteca Universitaria de Salamanca (Ms.2478), es una copia incompleta en letra itálica del siglo XVI, que añade cinco refranes pero no reproduce otros. Existen tres ediciones modernas parciales, pues transcriben los refranes pero no incluyen las glosas: la más temprana fue dada a conocer por Francisco Navarro Santín en 1904; con posterioridad, lo hacen Louis Combet (1971) y Jesús Cantera Ortiz y Julia Sevilla Muñoz (2002). Más recientemente, Fernando Cantalapiedra Erostarbe y Juan Moreno Uclés (2006) editan la edición completa de los refranes y sus respectivos comentarios traducidos del latín, basándose en el manuscrito de la BNMadrid.

En general, se ha considerado la obra como anónima, pero en la última edición mencionada, Cantalapiedra y Moreno (2006:16-30) adjudican su autoría a Diego García de Castro, catedrático de Salamanca, Vicescolástico y Arcediano, perteneciente al círculo cercano a Juan Arias Dávila, titular de la diócesis de Segovia entre 1461 y 1497, con quien identifican al obispo destinatario de la dedicatoria del Seniloquium. Para ello, reconstruyen el contexto sociocultural e ideológico en el que se produjo y difundió el refranero. De este modo, lo conectan con el ambiente de reforma católica en el que intervino la orden de los jerónimos, comprometida en la lucha antihéretica, y del que también surgió la Inquisición, en cuyos tribunales y en los de jurisdicción real participó el obispo de Segovia, Juan Arias Dávila. En este ámbito desarrolla su episcopado durante el cual mostrará su preocupación por la formación del clero y el pueblo, que justificaría su asociación con este refranero, pues lo vería como el lenguaje sapiencial propio del pueblo que podía ser interpretado desde el punto de vista religioso y jurídico para sus fines didácticos y pastorales. En cambio, para Hugo O.Bizzarri (2004: 106-107), la obra está dedicada a la lectura escolar y, por ser su estudio anterior a la edición de Cantalapiedra y Moreno, no reconoce la identidad del autor, aunque acota que parece versado en Derecho canónico y Romano. Por otra parte, observa que la confección del manuscrito matritense ofrece la primera edición de una colección, al presentar una disposición tipográfica de los refranes: orden alfabético y refranes resaltados con tinta roja respecto de las 
glosas, que a su vez, merecieron anotaciones marginales de un lector atento. Esta observación de Bizzarri nos hace pensar que esta copia del refranero fue concebida para ser impresa, aunque circunstancias eventuales no permitieron que llegara a las prensas, probablemente por no haber imprentas en la fecha de su composición, si aceptamos su procedencia segoviana.

El refranero comienza, entonces, con una dedicatoria a un obispo no identificado, hecha por un clérigo de su entorno que firma Castro. Luego se inserta un epígrafe que titula y define la obra: "Comienza este libro, que se llama Seniloquiun, el cual se debe considerar como libro de leyes y antiguo por los motivos que siguen" (2006: 47). Estos conceptos se van a explicar en el espacio prologal, ordenando los argumentos y las citas de autoridad para fundamentar tres aseveraciones, que configuran el discurso en una estructuración tripartita:

En primer lugar afirmo que los proverbios se llaman ley antigua, pues se suele decir "es un antiguo proverbio"...

En segundo lugar mantengo que la vejez $o$ antigüedad debe venerarse o reverenciarse, porque, aquello que los antiguos dicen debe considerarse como Derecho...

En tercer lugar afirmo que los antiguos o populares proverbios se deben considerar como Derecho... (2006: 47)

La argumentación tiende a justificar, por una parte, la valoración de la ancianidad y su asociación con la ley, cuya autoridad se coloca inmediatamente después de las Sagradas Escrituras. Por otra, la estimación de los refranes en cuanto normas consuetudinarias emanadas de la sabiduría de los antiguos. Estos juicios se refrendan no sólo con las citas bíblicas, de los comentaristas o de Aristóteles, sino también con la mención de proverbios. Este procedimiento se va a reiterar continuamente en la escritura de las glosas latinas que comentan los refranes. En estos comentarios se despliega la erudición del autor que está en consonancia con su aprecio y conocimiento de las formas paremiológicas populares. ${ }^{1}$ Sin embargo, muchas veces las interpretaciones y aplicaciones propuestas fuerzan el sentido de los refranes, o se realizan inferencias bastante laxas, de tipo jurídico o moral; incluso suelen explicarse a partir de referencias históricas, anécdotas o relatos literarios.

77. Comadre andariega, donde vo, allá vos fallo.

Entre todos los cristianos hay una única fe, pues en la Galia, Bretaña, África, Persia y Oriente, India y todas las naciones extranjeras adoran a un único Dios y observan una única norma de verdad. Jerónimo lo comenta en su Carta al obispo Evandro. Ya que en toda la tierra se divulga la doctrina de aquellos apóstoles y sus palabras hasta el límite del mundo. Este proverbio puede aplicarse a las

\footnotetext{
${ }^{1}$ La crítica más reciente coincide en destacar la dignificación del refrán que implica el Seniloquium. Según Cantalapiedra y Moreno (2006: 41), el autor valora los refranes como manifestaciones del Derecho tradicional, pues reconoce su prestigio dado por la antiguedad y el carácter sentencioso. Esta apreciación del refrán se acompaña con la erudición y cultura que reflejan las glosas. Entre los temas e ideas que aparecen en los comentarios, mencionan la creencia en la religión católica, el antisemitismo, la misoginia, la aceptación de la monarquía -el rey está por encima de la ley de los hombres-, la fuerza del amor patemal, mayor que el filial. El autor se muestra tradicional y respetuoso con la ancianidad. Por esto, sostienen que su intención es educar al pueblo en los contenidos de la ley, el Derecho Civil y Canónico, con el lenguaje de la paremiología, es decir, del refranero como lenguaje sapiencial popular. Para Bizzarri (2004:107), el Seniloquium presenta la jerarquización del refrán al nivel de auctoritas, puesto que se los comenta como si fueran verdaderos dichos de los Padres de la Iglesia o pasajes bíblicos.
} 
mujeres que, en la época del abad Valentín, hacían de comadres de los monjes y acudian de todos lados a los monasterios. También puede referirse a las monjas, que se obcecan con las ataduras de la honestidad, con la modestia monacal y con la vergüenza del sexo, aunque salgan fuera de su monasterio y convivan en las casas de personas del mundo. $\mathrm{Y}$ puede aplicarse igualmente a los primados, quienes, aunque deben residir en una sola ciudad, andan errantes por las villas; lo que no deben hacer. Gregorio lo explica en la Carta al patricio Gerendo, ex arzobispo de África. Alude el proverbio a los clérigos que intervienen en espectáculos y en comilonas opulentas, lo que no es conveniente. Y a aquellos clérigos, que se van a peregrinar sin mandato del obispo. Incluso este proverbio puede decirse del Señor Dios nuestro, de quien alguien piensa que puede esconderse en vano. En efecto, sobre esto dijo el profeta: "Si subo al cielo, tú allí estás; si desciendo al inferno, también estás". Sobre este versículo poetizó el maestro Anselmo: "A donde huyas, católico, a donde subas, siempre estarás a la vista de Dios". Ni siquiera los recónditos tabernáculos pueden ocultar las miradas del juez, que todo lo observa. (2006: 100-101)

Este ejemplo parte de una interpretación religiosa que fuerza el sentido del refrán en cuanto expresión popular; la exégesis cristiana, en cambio, se autoriza con las citas bíblicas y patrísticas. Sin embargo, cuando se enumeran los distintos casos de aplicación moral a la conducta de los clérigos, encontramos una mayor correspondencia con la acepción tradicional. ${ }^{2}$

También se puede constreñir una interpretación asociándola al campo del derecho: tal sucede con el dialogismo que se recoge en el № 67. ¿Cómmo te fesite caluo? - Pelo a pelo, pelando, cuya glosa comienza "Poco a poco si no se usa una ley, e incluso obrando contra ella, se termina olvidándola por completo y cae en desuso..." (2006: 92). Sin embargo, en otras paráfrasis de carácter jurídico, la distancia semántica suele ser no tan pronunciada:

\section{A poco caudal, pauca ganancia.}

Se debe repartir la ganancia entre los socios, según la cantidad del capital que cada uno de ellos haya invertido en la sociedad, si hubo [sic] igual aportación de capital. Lo decreta Justiniano. Los socios no gozan de iguales dividendos, si alguno aportó más trabajo, más destreza, más dinero. El que aportó a la sociedad más dinero o más trabajo o cualquier otra circunstancia, debe conseguir mayor ganancia de la sociedad. (2006: 86-87)

Observamos aquí al refrán funcionando como norma legal, que determina las pautas para el reparto de los beneficios obtenidos en una sociedad, según la inversión realizada. También puede explicarse el proverbio relacionándolo con algún suceso histórico o anécdota particular:

\footnotetext{
${ }^{2}$ El sentido tradicional, creo que es recuperado en la Glosa de 1541 a los Refranes que dizen las viejas tras el fuego, cuando el comentarista explicita en su acotación: "El poco sossiego nota es de liuiandad" (2001: No 161, p.173)
} 
168. El villanno, quando se ensanna, en su mal ensencha.

Este proverbio alude al emperador Federico, a quien se le ató con la cadena de la excomunión por sus excesos. El Papa Inocencio envió nuncios especiales y hombres de gran autoridad, como tres cardenales, quienes le propusieran que el propio Papa y los cardenales querían hacer la paz con él. Y si la Iglesia en algo le había perjudicado, que estaba dispuesta a corregir y a devolverlo al estado debido. Sin embargo, sobrepasando la dureza de un Faraón, despreció los ruegos y consejos del Papa, exasperando al máximo su obstinación, por ello fue privado de su dignidad y de todo honor. (2006: 158-159).

Otras veces, la relación puede darse de manera inversa cuando el relato parece creado para explicar la paremia. Tal es el caso del refrán $\mathrm{N}^{\circ} 134$. El dardillo de Burgos, quitadlo et séase vuestro (2006: 135), en el que se construye una anécdota a partir de los datos que ofrece el refrán, el cual resulta incomprensible sin un contexto interpretativo. La Biblia ofrece abundante material narrativo para ilustrar refranes, con mayor o menor propiedad; así sucede en el breve ejemplo del $N^{\circ} 49$. Al buen compannon, buena companja, cuya glosa establece una sucinta analogía con un episodio evangélico registrado en Mt. 17, 22-27: "Tal alianza hace el Señor con Pedro, cuando le manda dar como impuesto por ambos la moneda que encontró en la boca de un pez." (2006: 83). También puede recurrirse a narraciones literarias de amplia difusión, como el exemplum de los griegos y los romanos -que relata la transmisión de las leyes de una cultura a la otra y tiene una versión magistral en el Libro de buen amor-, aplicado en el Seniloquium al proverbio 328. Piensa el ladrón que todos han su coraçón (2006: 252). Otro conciso caso literario aparece cuando se explica el refrán con la cita de dos sentencias prácticamente similares, atribuidas a Horacio y Ovidio respectivamente: "331. Palabras y plumas, el viento las lieva. Dijo efectivamente Horacio: 'La palabra una vez emitida vuela irrevocable'. Y también Ovidio: 'La palabra una vez emitida vuela irrecuperable'." (2006: 254255).

Más allá de estos aspectos compositivos y de la reconocida jerarquización de los refranes, como enunciados merecedores de una exégesis propia de la Biblia y de los autores clásicos, quiero destacar la confluencia de saber erudito y popular que se da en el Seniloquium. En esta convergencia de cultura letrada y tradicional, encuentro la constante caracterizadora del discurso proverbial en la trayectoria histórica de la paremiología castellana y en la convivencia de sentencias y refranes en textos literarios espafioles. Sin embargo, esta relevancia que le adjudico al Seniloquium, desde la perspectiva que nos da el tiempo, no se corresponde con la recepción en su época de producción y transmisión, probablemente limitada por la condición manuscrita de la obra y el circuito escolar de su difusión.

\section{Refranes que dizen las viejas tras el fuego}

Una situación muy distinta ocurrió con los Refranes que dizen las viejas tras el fuego, compilación atribuida al Marqués de Santillana, que tuvo un enorme éxito editorial como lo testimonián las cinco impresiones que se sucedieron en la primera mitad del siglo XVI (1508, 1509 ó1510, 1522, 1541 y 1542). De ellas se destaca la edición de 1541, realizada en Valladolid por Francisco Fernández de Córdoba, por presentar los refranes acompañados con breves glosas sentenciosas. Hay también varias ediciones modernas, que son otra muestra del interés 
suscitado por esta recopilación a través de los siglos. No parece necesario insistir en su importancia como primer refranero impreso e iniciador de una larga práctica editorial que llega hasta nuestros días.

En el título, además de su adjudicación al Marqués del Santillana, se mencionan los motivos de su recopilación y el modelo compositivo elegido: "Iñigo López de Mendoça a ruego del rrey don Juan ordenó estos refranes que dizen las viejas tras el fuego y van ordenados por el [orden del] a.b.c.". La cuestión de la autoria se inició con Foulché Delbosc, cuando en su edición de 1911, bajo el nombre de Urban Cronan, negó la atribución del refranero a Santillana. Sin embargo, pese a la excepción eminente de Kerkhof y Gómez Moreno (1988), la mayoría de los especialistas como Lapesa (1957), O’Kane (1959), Combet (1971), Pérez Priego (1992), Bizzarri (1995 y 2004), han argumentado a favor de la autoría del noble castellano. En consecuencia, ha de considerarse la época de recopilación de los refranes anterior a 1458, año de la muerte de don Inigo. Atendiendo al epígrafe de la obra, sabemos que se compuso para el entorno cortesano del rey, según la costumbre de ofrecer colecciones de proverbios a los monarcas, que encontramos representada ya en el siglo XI con la obra de Wipo dedicada a Enrique IV de Inglaterra. El mismo Marqués de Santillana compone sus Proverbios o Centiloquio por encargo de Juan II para la educación del príncipe don Enrique. Estas obras se entroncan con la corriente culta de la literatura de sentencias del siglo XIII: algunas, como Poridat de las poridades y el Libro de los doze sabios, están emparentadas con el género de los espejos de príncipe; otras, como Bocados de oro y el Libro de los buenos proverbios, son compilaciones de paremias atribuidas a filósofos antiguos, bajo cuyo nombre se yuxtaponen sentencias, dichos, dialogismos que configuran los consejos y enseñanzas de los mencionados sabios. (Ramadori, 2001). Además, los Refranes se vinculan con el ámbito escolar, dado que emplean uno de los modelos compositivos más antiguos -la disposición de una serie de proverbios en orden alfabético- que, en la ensefianza medieval, constituía un método didáctico para la sistematización de diferentes materias $\mathrm{y}$, a la vez, un recurso mnemotécnico empleado en el estudio.

Por otra parte, hemos de tener en cuenta que las ediciones del siglo XVI tienen un contexto de recepción diferente. Como observa Bizzarri (2004: 69), surge entonces una nueva masa de lectores perteneciente a la burguesía que se inclina por una literatura breve, transmitida en los pliegos sueltos, a través de los cuales se introduce el refranero en el mercado editorial. De este modo, se da un cambio decisivo: "aquel que va de la compilación personal y privada, elaborada para un círculo reducido y próximo, al de la compilación orientada a un público burgués lector." (Bizzarri, 2004: 89). A ello se suma que los editores pueden llegar a participar activamente sobre la materia paremiológica, así las variantes que suelen presentar las distintas impresiones pueden explicarse porque superpusieron las versiones por ellos conocidas a las originales. Quizá también, en algunas ocasiones, hayan intervenido en el proceso de sedimentación que se opera con algunos refranes cuando se les agrega una coda explicativa para esclarecer su sentido. La necesidad de explicar los proverbios puede deberse a la gradual diferenciación que comienza a producirse entre saber culto y popular. Así se expresa en la sucinta presentación de la edición glosada de 1541: 
Yñigo Lopez de Mendoça por mandado del Rrey don Juan ordeno y copilo los rrefranes castellanos que se dizen comúnmente entre todo genero de personas, los quales comprehenden en si sentencias muy prouechosas y apacibles no empero tan manifiestas que puedan tan facilmente ser entendidas de todos $y$, por tanto, los gloso breuemente vna persona docta a gloria de Nuestro Señor y prouecho y consolacion de los cristianos, especialmente de los de nuestra nacion, y la glosa es breue por quitar fastidio y dar contento a los lectores. $\mathrm{Y}$ van puestos los refranes por la orden del abece, $y$, junto a cada refran, la glosa o sentencia, la qual se a hecho agora nueuamente. (2001: 162)

En estas palabras observamos que, a pesar de la tradicionalidad propia de los refranes, otros rasgos distintivos, como el carácter costumbrista y situacional o el valor de código ético que le otorga la comunidad de origen, pueden provocar dificultades de comprensión con el transcurrir del tiempo o su migración a otras regiones. A esto se suma la adaptación moral que realizan las glosas de la edición de 1541 sobre la -por momentos- acomodaticia filosofia de los Refranes que dizen las viejas tras el fuego, con sus consejos prácticos en beneficio del individuo y de la obtención de ventajas en sus relaciones sociales.

\section{Biua la gallina con su pepita.}

La vida, aunque con trabajos, naturalmente es amada de todos.

143. Cada gorrión a su espigon.

En la nescessidad ninguno guarda amistad, y el que haze lo que puede, cumple lo que deue.

180. Capato roto o sano mas vale en el pie que en la mano.

Mas vale bien obrar aunque con tibieza que no estar ocioso y descuydado

384. La una mano laua la otra y las dos al rostro.

Los que son de vna comunidad deuense ayudar en la nescessidad.

423. Mata que el rey perdona.

La vana esperanza prouoca a hazer desconciertos.

(2001: 170, 172, 174, 190 y 192)

En este refranero encontramos diversas formas paremiológicas que, si bien se incluyen dentro de la fraseología popular, varian desde simples expresiones habituales a formulaciones líricas. Estas últimas muestran la influencia que tuvo el refrain provenzal, más allá de la cuestión terminológica. Bizzarri (1995: 12-16) propone una tipología que reconoce, en primer lugar, el dicho popular, caracterizado por ser frecuentemente una comparación con una estructura bipartita: 179. Callar como negra en baño. 675. Tanto pan como queso. También aparecen frases proverbiales que se diferencian del refrán por ser gramaticalmente incompletas y necesitar del contexto para su plena significación: 103. Agua tras harina va. 568. Sobre cuernos penitençia. Un tercer grupo de refranes se integra con aquellos que poseen una parte final explicativa de su sentido: 261. El perro del ortelano: ni come las verças ni las dexa comer. 387. Los perros de Çorita: pocos y mal auenidos. También hay algunos dialogismos: 196. ¿De donde quebró esta astilla? Deste mal madero. 611. ¿Quien vos fizo alcalde? Mengua de 
ombres buenos. En número menor se recogen algunas formas líricas no sentenciosas: 174 . Campanillas de Toledo, oygo vos y no vos veo. 677. Tan lueñe de ojos, tanto de coraçon. Estos últimos ejemplos llevan a la cuestión del carácter lírico que los primeros críticos, como Amador de los Ríos (1862), establecieron para los refranes. Si bien en la actualidad se ha desestimado la presencia de formas métricas en los refranes, sin embargo, aún se les reconoce cierto estatuto poético. Bizzarri aclara que sólo los refranes literarios poseen una naturaleza rítmica, resultado de la transformación del refranero en su puesta por escrito y de sus contactos con las producciones líricas. Los Refranes de Santillana se caracterizan especialmente por su musicalidad, que se basa en los recursos de la rima y de una sintaxis elaborada melódicamente por medio de paralelismos sintácticos y binomios, sumados a la utilización de estructuras que generan la candencia de la formulación. En definitiva, concluye que éstos "son los pilares sobre los que se asienta la naturaleza rítmica de los Refranes, tal vez exacerbada por su colector, que al aislarlos de su contexto los aderezó como piezas artísticas dispuestas a ser exhibidas en la sala de un palacio." (Bizzarri, 1995: 26). Esta elaboración literaria del refrán es una de las causas por las que Bizzarri objeta la utilización de los refraneros como medio de indagación del refrán popular. Sin embargo, no podemos desconocer el papel fundamental de los Refranes que dizen las viejas tras el fuego para el desarrollo de la tradición paremiológica española. Quizá lo que haya atraído a los letrados de los siglos posteriores, a pesar de su proclamado interés por el saber popular, fuera precisamente la recreación literaria de las formas tradicionales. En la investigación que vengo desarrollando sobre el discurso proverbial, constituyo a las paremias como objeto de estudio literario y propongo una aproximación literaria a la cuestión de la trayectoria histórica y de las relaciones estructurales, contextuales e ideológicas entre enunciados paremiológicos y textos literarios. ${ }^{3}$ La obra del Marqués de Santillana resulta una pieza esencial en este entramado discursivo.

\section{Refranes famosissimos y prouechosos glosados}

Este refranero también constituye otro jalón importante en el trazado del mapa paremiológico, en particular porque estuvo en abierta competencia con los Refranes del Marqués de Santillana en el mercado editorial del siglo XVI. Ambas colecciones comparten una historia impresa semejante: se conservan siete ediciones antiguas de los Refranes glosados, que tambiên se realizan en la primera mitad del siglo XVI, más una impresión valenciana de 1602 corregida y enmendada por el bachiller Esteban Gómez, adaptándola al gusto linguístico de su época. A partir del siglo XIX se inicia la serie de ediciones modernas hasta la última de H.O.Bizzarri en el año 2009. En la tradición impresa primitiva encontramos dos rótulos para nombrar el libro: uno más breve, Refranes glosados, y el segundo más detallado, Refranes famosissimos y prouechosos glosados.

\footnotetext{
${ }^{3}$ La investigación sobre el discurso proverbial se inició con mi tesis doctoral, centrada en el estudio de aspectos estructurales y estilísticos de la literatura de sentencias en la Castilla del siglo XIII. Luego fue continuada en proyectos grupales que dirijo en el Centro de Estudios Medievales y Literatura Comparada de la Universidad Nacional del Sur desde el 2006, cuya etapa actual está dedicada a la obra del Marqués de Santillana.
} 
Otra similitud entre el refranero de Santillana y los Refranes glosados se centra en el uso de encabezados que sirven para contextualizar las obras. En este caso, el epígrafe refiere la situación didáctica en la que un padre anciano adoctrina a su hijo para que viva con discreción, mediante consejos constituidos por refranes: "Un muy virtuoso hombre allegandose a la vejez, considerando que los días de su beuir eran breues, deseando que vn solo hijo que tenia fuesse sabiamente instruido y consejado, para que discretamente biuiesse, de los presentes prouerbios y refranes le dotrino" (2009: 247). A continuación se inserta un breve prólogo donde se completa esta contextualización valorando el saber adquirido por la experiencia de vida, como único tesoro que el padre puede dejar a su hijo antes de la muerte. Pero aún más destacable resulta que los refranes, como condensación de esa sabiduria, alcanzan la misma estimación que las sagradas escrituras y los filósofos antiguos. Así pues, los proverbios tradicionales se aprecian como código ético que sirve no sólo para lograr el comportamiento adecuado sino también la salvación eterna.

Hijo mio dialectissimo, aprende escuchando la dotrina de mi, padre tuyo, que naturalmente te amo. Ca yo llegado al peligroso puerto de estrema vejez y fecho vezino de la incierta hora de la muerte, no podiendote bien heredar con bienes de fortuna, he pensado y deliberado de algunos buenos y prouechosos exemplos instruir la tu juuentud. E assi como los dotores y virtuosos eclesiasticos acostumbran dar lumbre para yr a la vida celestial y sciencia con autoridades de la sagrada escritura, assi yo por que passes bien el camino de aquesta transitoria vida te informare con la diuinal ayuda de aquel saber que platica de antiguos días me ha mostrado y esperiencia de muchas cosas me ha subido a maestro. Donde traere por autoridad de aquesta prouechosa licion aquellos prouerbios y refranes que los nuestros pasados antiguamente platicauan y avn hasta oy los honorables ancianos y reuerendas mugeres como a dichos de filósofos allegar acostunbran. Porque ayudado por la lectura de aqueste breue tratado y acompañado de la diuina gracia, hagas tales obras que [pasando] por las aduersidades de aqueste miserable mundo, merezcas alcançar la bienauenturança para que eres criado. Y porque mejor esto puedas comprehender y retener, partirte [he] esta poca escritura en doze breues capitulos. (2009: 247-249).

Los Refranes glosados se estructuran, entonces, en doce capítulos. Así, los dos primeros capítulos desarrollan la temática del control de la palabra y del consejo, respectivamente. En los tres siguientes dedicados a cuestiones domésticas, se reflexiona sobre las mujeres (cap.3), centrando luego el tema en la esposa (cap.4), para concluir con recomendaciones sobre la organización y economía de la casa (cap.5). Los últimos seis capítulos recogen una serie más variada de advertencias para guiar el comportamiento: no pleitear con los superiores (cap.6), practicar la limosna (cap.7), adquirir y usar discretamente la hacienda (cap.8), tener prudencia en los negocios (cap.9), evitar los malos vicios (cap.10), ser constante en el buen obrar (cap.11) y cuidarse de los malos amigos (cap.12). Estos temas están mencionados en los títulos que llevan cada uno de los capítulos, aunque en ellos se desarrollan otros contenidos además de los indicados en los epigrafes. Sin embargo, el discurso se organiza 
siempre sobre la base casi excluyente de los refranes, que se subordinan en función del desarrollo de un tópico que les da coherencia semántica y se conectan entre sí configurando la sintaxis textual. Así sucede desde el capítulo I donde se trata el tema de no hablar mucho:

Loan todos los discretos el poco hablar, pues es vezino del buen callar, ca es cierto que el que calla no puede errar ... Fabla pues poco, piensa mucho con temor de lo que se dize: Palabra no se puede tornar pues que es dicha. E el refran $\tan$ verdadero que: Quien mucho fabla mucho yerra. E después muchas vezes el largo hablador encendido en su hablar ni quiere oyr ni dar lugar de responder. $\mathrm{E}$ assi poco pensando y mal atentando dize alguna razón que sería mejor haberla callado. E serán palabras para si mismo dañosas. Y merezca oyr: Habla Roldan y habla por tu mal. Pues que tomado y reprehendido por indiscreta confession de su boca, podrían decir: Al buey por el cuerno y al hombre por la palabra. Atientate y refrenate, hijo mio, y tal no te acontezca. Recuerdate y desprende que por tal se dixo: En boca cerrada no entra mosca. Aquesto es el que calla no yerra. (2009: I, 250-251)

El texto está construido como una ilación de refranes que se van entretejiendo en una exposición de preceptos condensados por las paremias, apenas enlazadas por enunciados conectores. Así la noción principal se expresa con el proverbio: el que calla no puede errar, repetido como cierre del segmento discursivo, con una leve variante que refuerza la aseveración de la idea: el que calla no yerra. Los otros refranes comparten el mismo foco conceptual con lo que se logra una mayor demostración de los juicios aconsejados. Por otra parte, suelen estar destacados con fórmulas introductorias que los autorizan como manifestaciones de un saber verdadero y refrendado por la experiencia.

Si en el Seniloquium observamos la jerarquización de los refranes al ser considerados merecedores de una exégesis erudita propia de los textos bíblicos y clásicos, en los Refranes glosados la estimación de estos enunciados tradicionales se muestra en la confección de un discurso aleccionador a base del entretejido exclusivo de refranes.

A partir del modelo discursivo que Refranes glosados emplea en la disposición de estas paremias tradicionales, se puede establecer una conexión con la literatura de sentencias del siglo XIII. Estos textos también constituyen manuales de conducta que en su configuración discursiva integran proverbios pero de procedencia culta, en función del desarrollo de tópicos sapienciales. ${ }^{4}$ Así, Poridad de las poridades o Secreto de los secretos recogen los consejos que Aristóteles envió a Alejandro Magno para guiarlo como gobernante; en consecuencia, se relacionan con la tradición de los espejos de príncipes:

Alexandre, todo rey que faze so regno obediente a la ley merece regnar; et el que faze desobediente el regno a la ley, aquel desama la ley, et qui desama la ley, la ley lo mata. Yo uos digo lo que dixieron los philosofos que la primera cosa que

\footnotetext{
${ }^{4}$ Otros aspectos compositivos que comparten son la existencia de prólogos contextualizadores y la división de capítulos acompañados con títulos. (Ramadori, 2001).
} 
conuiene a todo rey es guardar todos los mandamientos de su ley, et que muestre al pueblo que el tiene firme mientre su ley et que la uoluntad se acuerde con el fecho; que si la uoluntad del se acordare, non puede que Dios et los omnes no lo entiendan, et con esto sera Dios pagado et los omnes del. (1957: 36$)$

Los consejos de Aristóteles recomiendan al monarca el respeto por la ley por medio de expresiones sentenciosas, autorizadas doblemente por su adjudicación al sabio griego y por la mención explícita de los filossofos.

Flores de filosofia y el Libro de los cien capitulos también contienen materia éticopolítica, aunque están dirigidos a un destinatario más amplio y generalizado. El comienzo de Cien capitulos puede servir para mostrar el modo de conformación textual de las obras discursivas:

E fabla este primer capitulo de las leyes, de los reyes e de los señores; e que es ley, o que es [rey]. Ley es [çimiento] del mundo, e rey es guarda de aquel çimiento; e toda labor que(l) non ha çimiento es guisado de caer; e todo çimiento que non ha guarda es guisa[do] de desfazerse. Ley e rey son dos cosas que han hermandad en uno; e el rey ha menester ayuda de la ley, e la ley ha menester esfuerço del rey. Con tres cosas se mantiene el reyno: con rey, con ley e con espada. Con ley se mantiene el rey, e el rey es guarda de la ley, e la espada es castillo del rey, ca do quieren reyes alla van reyes e leyes. (1960: I, 1)

En el inicio se fija el tema o tópico del discurso, similar al ejemplo transcripto de Poridades: la definición de ley y rey. También en este caso, advertimos la escritura proverbial en la forma concisa y el estilo figurado que adquieren los períodos oracionales; incluso, la última frase reproduce un refrán: "ca do quieren reyes alla van reyes e leyes", introducido por un conector causal. La presencia de este refrán ilustra el uso indiferenciado de proverbios cultos y populares, que se hace en la literatura sapiencial del siglo XIII y se comprueba igualmente con la inserción de variadas formas paremiológicas en textos literarios de diferentes géneros.

Asimismo los textos sapienciales del siglo XIII y Refranes glosados comparten la utilización de relatos breves, aunque con diferente tratamiento. En la literatura de sentencias, se destaca la doble función didáctica y retórica que se les adjudica a estos relatos transformándolos en exempla. Veamos una muestra en Poridat:

Alexandre, non mato al rey en Egio si non que su uoluntad era mas de dar que su renta, por que ouo mester de tomar aueres de sos omnes, et por esso leuantaronse sobrel los pueblos et fue destroydo so regno. Et de la franqueza es dexar omne que por las tachas encubiertas que son en los omnes que non demande nyn las quiera saber, et que non retayga lo que da; et que non pare mientes al yerro del torpe. (1957: 34) 
El exemplum se inserta para aleccionar sobre la práctica de la franqueza o liberalidad y responde al procedimiento de uso común en Poridat: cumple una función retórica como prueba dentro de una argumentación, al mismo tiempo que guarda una estrecha correspondencia entre el tópico del discurso y el asunto del exemplum. (Ramadori, 2001: 123-126).

En los Refranes glosados, además de responder a una intención ilustrativa, la interpolación de narraciones cumple otras aplicaciones: puede crear un contexto explicativo, a partir del carácter situacional inherente al refrán, así como explicitar el sentido del proverbio, e incluso, en algún caso excepcional interpretarlo alegóricamente. ${ }^{5} \mathrm{El}$ "Capítulo IX. Como te deues auer prudentemente en tus negocios" resulta especialmente adecuado para ejemplificar la inserción de relatos breves, por cuanto en su mayor medida está construido como un enhebrado de narraciones, que sirven para explicar e intercalar refranes. Transcribo sólo el primer relato:

De aquestos siguientes enxemplos te ruego, fijo mio, quieras tomar la intención, y en su tiempo y lugar podras muy bien seruir. Fue vn hombre de estima que, caminando vn dia en compañía de vn recuero loco y atreuido, quiso contender con el de palabras, el qual con vn açote que tenia en las manos con que guiaua sus bestias dio al principal hombre por encima de las orejas con mucho deshonor. Por lo qual dixeron los miradores que assi pertenescia: $A$ bestia loca, recuero modorro. E fue bien dicho pues hallo çapato de su pie. (2009: 286)

En este caso, se establece una relación filiativa entre refrán y relato pues éste vale para declarar el origen de la paremia. Además, se agrega otra frase proverbial que reafirma el sentido otorgado al refrán y la validez de la historia contada.

Los puntos de contacto entre los Refranes glosados y la literatura sapiencial del siglo XIII son otra prueba más que demuestra la convivencia de las dos vertientes, erudita y popular, de la tradición paremiológica en la Edad Media. Así como insistimos en la coexistencia de distintas formas proverbiales en los textos, también podemos extender esta confluencia a los modelos de conformar las colecciones, tanto de sentencias como de refranes.

Aunque se pueden reconocer diferencias nítidas entre la literatura sapiencial (finalidad didáctica, propuesta de paradigmas culturales, motivación ideológica) y los refraneros (código ético, valoración de la experiencia de los viejos, carácter costumbrista y situacional), también se pueden establecer paralelos, especialmente en el aspecto compositivo. En primer lugar, la procedencia escolar de los modelos estructurales; al igual que el aprecio de la paremiología por parte de autores letrados. Los contextos de producción y difusión se orientan hacia círculo del rey como primer destinatario, pero también se da una apertura a un estadio de recepción más general, que la imprenta proyectará en un nuevo lector identificado con la burguesía. En aspectos formales más específicos, las recopilaciones letradas yuxtaponen las listas de

\footnotetext{
5 "En muchas maneras so cierto, hijo mio, que en los desbaladeros de muchos vicios desbararas. Mira bien que no te dexes caer ni pierdas la rienda de la descrecion, que: Estropeçar y no caer, auentaja es de camino. Guarda que cae la virtud y se quiebra perdiéndose. Traya vn hombre vn asno cargado de vidrio, al qual demandaron que traya alli. $\mathrm{Y}$ el respondió: No nada, si el asno cae. La nuestra fragile sencualidad es el asno. Y nuestras obras son vidrio. Y estonces ellas se quiebran y tornan en anda quando desbarando y estropeçando caemos en algún vicio." (2009: XI, 293).
} 
sentencias bajo el nombre de un sabio o conjunto de ellos, mientras que en los refraneros también encontramos series de proverbios autónomos pero, en este caso, privilegian la ordenación alfabética de las paremias, como ejemplifican los Refranes del Marqués de Santillana. Por otra parte, desestimando la organización compilatoria, los Refranes glosados recurren al modo discursivo de integrar entre sí las locuciones proverbiales, de acuerdo a los principios de la cohesión semántica y la subordinación sintáctica propios de esta modalidad. Su novedad consiste en emplear este modelo reemplazando las sentencias cultas por los refranes, en una exitosa valoración las formas tradicionales. En Seniloquium tenemos los refranes ordenados por a.b.c. pero con la originalidad de acompañarlos con glosas latinas, que interpretan su sentido y ellas mismas incluyen proverbios. Presenta una amalgama de saber popular y letrado en correspondencia con el modo compilatorio de los refranes y el discursivo de los comentarios en prosa latina. Todos los textos comparten el uso indistinto de diferentes formas paremiológicas, así como entablan estrechos vinculos estructurales y funcionales entre proverbios y narraciones breves. Por lo tanto, puede concluirse que las tres obras estudiadas, Seniloquium, Refranes que dizen las viejas tras el fuego y Refranes glosados, marcan el derrotero de la paremiología castellana más allá de la transmisión de un importante caudal de proverbios. Se constituyen en paradigmas de composición para los siguientes refraneros que los emularán e imitarán hasta la actualidad. 


\section{Referencias}

BIZZARRI, Hugo O. (ed.). 1995. Iñigo López de Mendoza, Marqués de Santillana, Refranes que dizen las viejas tras el fuego, Kasel, Edition Reichenberger.

BIZZARRI, Hugo O. (ed). 2001. "La glosa de 1541 a los Refranes que dizen las viejas tras el fuego", Olivar, №2, Documentos, pp.157-216.

BIZZARRI, Hugo O. 2004. El refranero castellano en la Edad Media, Madrid, Ediciones del Laberinto, Colección Arcadia de las Letras, 28.

BIZZARRI, Hugo O. (ed.). 2009. Refranes famosissimos y prouechosos glosados, Lausanne', Sociedad Suiza de Estudios Hispánicos, Hispania Helvetica 19.

CANTALAPIEDRA EROSTARBE, Fernando y MORENO UCLÉS Juan (eds.). 2006. Diego García de Castro, Seniloquium, Valencia, Publicacions de la Universitat de València.

COMBET Louis. 1971. Recherches sur le 'Refranero' castillan, Paris, Société d'Édition Les Belles Letres'.

GOMEZ MORENO Ángel y KERKHOFF Maximiliam (eds.). 1988. Iñigo López de Mendoza, Marqués de Santillana, Obras completas, Barcelona, Planeta.

KASTEN Llyod (ed.). 1957. Poridat de las poridades, Madrid, University of Wisconsin.

LAPESA Rafael. 1957. La obra literaria del Marqués de Santillana, Madrid, Insula.

O'KANE Eleanor. 1959. Refranes y frases proverbiales españoles de la Edad Media, Anejos del B.R.A.E, Madrid.

PÉREZ PRIEGO Miguel Ángel. 1992. "La escritura proverbial de Santillana", Actas II Congreso Internacional de la Asociación Hispánica de Literatura Medieval, pp.643-651.

RAMADORI Alicia E. 2001. Literatura sapiencial hispánica del siglo XIII. Bahía Blanca, Ediuns.

REY Agapito (ed.). 1960. El libro de los cien capitulos, Bloomington, Indiana University Press.

Alicia Esther Ramadori: Doctora en Letras. Profesora asociada de Literatura Española en el Departamento de Humanidades de la Universidad Nacional del Sur. Directora del Centro de Estudios Medievales y Literatura Comparada de la UNS. Directora de Tesis de Doctorado y Proyectos de Investigación. Presidente de la Sociedad Argentina de Estudios Medievales. Autora de libros, capítulos de libros y artículos publicados en revistas académicas en el ámbito universitario nacional y en el internacional, en España, México y Brasil. 